\title{
Biosynthesis of phenylpropanoids and their protective effect against heavy metals in nitrogen-fixing black locust (Robinia pseudoacacia)
}

\author{
Nam Su Kim¹, Ramaraj Sathasivam¹, Se Won Chun', Woo Bin Youn², Sang Un \\ Park' ${ }^{1}$, Byung Bae Park ${ }^{2 *}$ \\ ${ }^{1}$ Department of Crop Science, ${ }^{2}$ Department of Environment and Forest Resources, Chungnam National University, 99 Daehak- \\ ro, Yuseong-gu, Daejeon 34134, Korea \\ *For correspondence: Email: bbpark@cnu.ac.kr, supark@cnu.ac.kr; Tel: +82-42-821-5747, +82-42-821-5730
}

Sent for review: 15 January 2020

Revised accepted: 23 April 2020

\begin{abstract}
Purpose: To examine the effect of various heavy metals (HMs) on phenylpropanoid pathway compounds in Robinia pseudoacacia.

Methods: A series of pot culture experiments were performed to understand how the metabolic profile of phenylpropanoid compounds were affected by various $\mathrm{HMs}$, such as redox-active $\mathrm{HMs}_{(\mathrm{AgNO}}$ and $\mathrm{CuCl} 2$ ), and non-redox-active $\mathrm{HMs}\left(\mathrm{HgCl}_{2}\right)$. Phenylpropanoid compound level was evaluated by high performance liquid chromatography.

Results: The total phenylpropanoid level in leaves increased significantly in all the treated groups when compared to that in the untreated group $(p<0.05)$. However, a significant effect on the total phenylpropanoid levels was only found for redox-active HMs $(p<0.05)$, whereas non-redox-active HMs showed less accumulation. Chlorogenic acid and rutin were the two major phenylpropanoid compounds found after the plants were subjected to redox and non-redox-active HMs stress. However, when compared to these two compounds, the levels of catechin hydrate, epicatechin, p-coumaric acid, kaempferol, and quercetin were lower. Caffeic acid level was significantly decreased in both redox and non-redox-active HMs when compared to that in the control $(p<0.05)$. In addition, trans-cinnamic acid accumulation was altered based on the types and concentration of HMs.

Conclusion: Phenylpropanoid metabolic pathway participated in the HM tolerance process for the protection of $R$. pseudoacacia from oxidative damage caused by HMs, thus allowing the species to grow in highly HMs-contaminated areas.
\end{abstract}

Keywords: Heavy metals, Non-redox-active metals, Phenylpropanoid compounds, Redox-active metals, Robinia pseudoacacia

This is an Open Access article that uses a fund-ing model which does not charge readers or their institutions for access and distributed under the terms of the Creative Commons Attribution License (http://creativecommons.org/licenses/by/4.0) and the Budapest Open Access Initiative (http://www.budapestopenaccessinitiative.org/read), which permit unrestricted use, distribution, and reproduction in any medium, provided the original work is properly credited.

Tropical Journal of Pharmaceutical Research is indexed by Science Citation Index (SciSearch), Scopus, International Pharmaceutical Abstract, Chemical Abstracts, Embase, Index Copernicus, EBSCO, African Index Medicus, JournalSeek, Journal Citation Reports/Science Edition, Directory of Open Access Journals (DOAJ), African Journal Online, Bioline International, Open-J-Gate and Pharmacy Abstracts

\section{INTRODUCTION}

Heavy metals (HMs) are a group of nonbiodegradable, long-lasting inorganic chemical compounds, which have deleterious effects on animals, humans, and plants. Few HMs, such as $\mathrm{Co}, \mathrm{Fe}, \mathrm{Mn}, \mathrm{Mo}, \mathrm{Ni}, \mathrm{Zn}$, and $\mathrm{Cu}$ are essential micronutrients [1]. However, at higher 
concentrations, they are highly toxic to plant tissue [2]. Robinia pseudoacacia ( $R$. pseudoacacia) belongs to the family Fabaceae. It is a woody legume commonly known as black locust or false acacia. It is mainly found in HMcontaminated areas and is widely used for the phytoremediation of HMs $[3,4]$.

In most plants, the accumulation of secondary metabolites is induced by abiotic stresses, signal molecules, or elicitors [5]. Among those metabolites, the phenylpropanoid pathway is one of the most important and often examined metabolic routes [6]. The products of this pathway play an important role in response to stress conditions [7]. Phenylalanine is the most important and common precursor for the synthesis of various phenylpropanoid compounds (Figure 1). In plants, several studies have investigated the effect of HMs on the metabolic profile of phenolic compounds [8-10].

The exact mechanism underlying the protective function of $R$. pseudoacacia against HMs are not clearly understood. This study was aimed to assess the potential roles of phenylpropanoids in $R$. pseudoacacia in protecting plants under $\mathrm{HM}$ stress. Particularly, the effects of various HMs on the phenylpropanoid content under greenhouse conditions were investigated.

\section{EXPERIMENTAL}

\section{Plant materials}

Seeds of $R$. pseudoacacia were collected from the experimental farm of Chungnam National University, Daejeon, South Korea, and germinated in a greenhouse in April 2018. Single seeds were placed in separate pots (size: $11 \times$ $11 \mathrm{~cm}$ ). The plants were grown up to $70 \mathrm{~cm}$, after which they were treated with various HMs.

\section{Heavy metal stress treatment}

The effect of $\mathrm{Ag}, \mathrm{Cu}$, and $\mathrm{Hg}$ toxicity on $R$. pseudoacacia was assessed using different concentrations of $\mathrm{AgNO}_{3}(10,50$, and $100 \mu \mathrm{M})$, $\mathrm{CuCl}_{2}(10,50$, and $100 \mathrm{mM})$, and $\mathrm{HgCl}_{2}(0.1,0.5$ and $1 \mathrm{mM})$. All the $\mathrm{HMs}$ were obtained from a commercial source (Sigma, St. Louis, MO, USA) and prepared for a stock solution; and the working concentrations were made from the standard stock solution. All the exposures concentrations were performed in triplicates.

\section{Determination of phenylpropanoid content}

After the HM treatments, the leaves of $R$. pseudoacacia were harvested weekly. The samples were freeze-dried at $-80^{\circ} \mathrm{C}$ for $72 \mathrm{~h}$ to assess the phenylpropanoid content by highperformance liquid chromatography (HPLC).

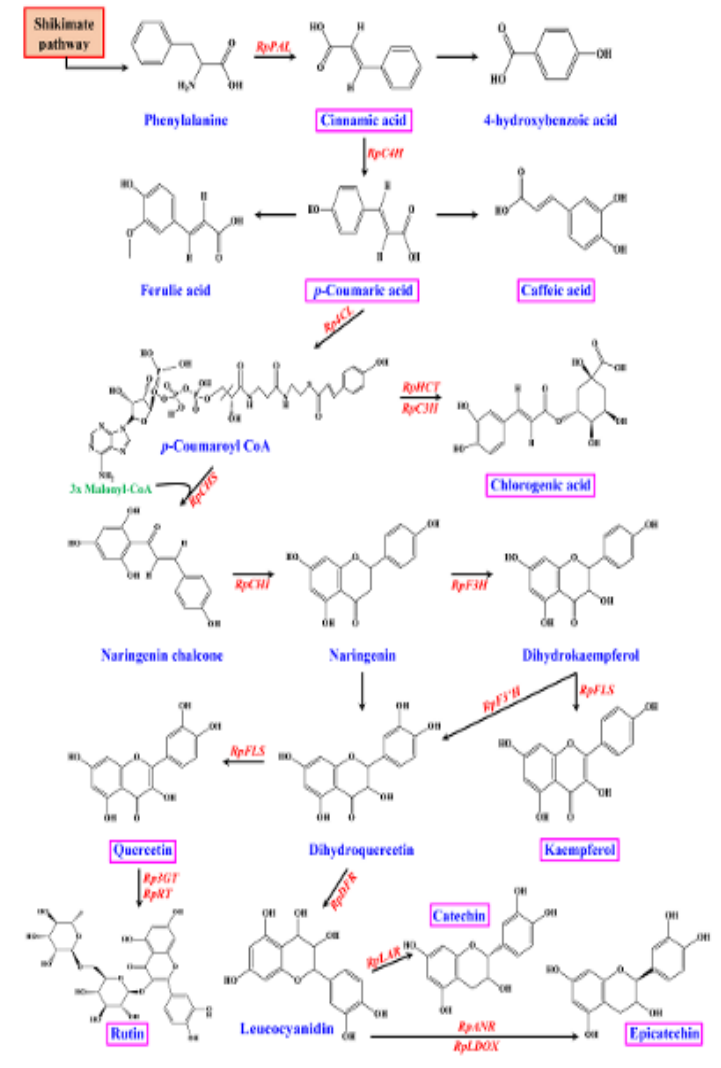

Figure 1: Proposed phenylpropanoid and flavonoid biosynthetic pathway in Robinia pseudoacacia. The enzymes responsible for enzymatic conversions reaction are shown in red color. The rectangle pink color box represents the phenylpropanoids and flavonoids analyzed in this study using HPLC. Abbreviations: $\quad 3 G T, \quad$ flavonoid-3-Oglucosyltransferase; 4CL, 4-coumaroyl CoA ligase; ANR, anthocyanidin reductase; $\mathrm{C} 3 \mathrm{H}, \quad p$ coumaroylester3-hydroxylase; $\mathrm{C} 4 \mathrm{H}$, cinnamate 4hydroxylase; $\mathrm{CHI}$, chalcone isomerase; $\mathrm{CHS}$, chalcone synthase; DFR, dihydroflavonol reductase; $\mathrm{F} 3$ ' $\mathrm{H}$, flavonoid-3'-hydroxylase; $\mathrm{F} 3 \mathrm{H}$, flavonone-3hydroxylase; FLS, flavonol synthase; HCT, cinnamoylCoA shikimate/quinate transferase; LAR, leucoanthocyanidin reductase; LDOX, leucoanthocyanidin dioxygenase; PAL, phenylalanine ammonia-lyase; RT, flavonoid 3-O-glucosiderhamnosyltransferase. Chemical compounds were drawn by using ChemDraw Ultra 12.0 software

The soluble phenylpropanoid compounds were analyzed using the previously described protocol of [11], with a slight modification. The stored samples were taken, and then crushed into powder using a mortar without solvent. For HPLC analysis, $100 \mathrm{mg}$ of each sample was taken and added to $3 \mathrm{~mL}$ of $80 \%$ aqueous $\mathrm{MeOH}$. The mixtures were vortexed for $1 \mathrm{~min}$ and then 
immediately sonicated for $60 \mathrm{~min}$ at $35^{\circ} \mathrm{C}$. The sonicated samples were centrifuged at $12,000 \times$ $g$ for $10 \mathrm{~min}$, and the supernatants were collected and filtered and sterilized with $0.45 \mu \mathrm{m}$ PTFE filters. High-performance liquid chromatography separation was performed on an Agilent 1260 Infinity Quaternary LC (Agilent Technologies, Inc, Germany) by reverse-phase chromatography using a C18 column $(250 \times 4.6$ mm, $5 \mu \mathrm{m}$, RStech, Daejeon, South Korea).

For the complete extraction of compounds, add $80 \%(\mathrm{v} / \mathrm{v})$ ethanol to the samples and incubated for $60 \mathrm{~min}$ at $25{ }^{\circ} \mathrm{C}$. The elution buffer used for HPLC elution of samples consisted of methanol:water:acetic acid $(98: 5: 1.5 \mathrm{v} / \mathrm{v})$ with a flow rate of $1 \mathrm{~mL} / \mathrm{min}$, and the column temperature was set at $29{ }^{\circ} \mathrm{C}$. The injection volume of the sample was $20 \mathrm{~mL}$, and the chromatographic detection of all phenylpropanoid content was carried out at $280 \mathrm{~nm}$. The phenylpropanoid contents were estimated based on standard peak area and the calibration curve. Quantification and analysis of samples were performed in triplicate.

\section{Statistical analysis}

The data are expressed as mean \pm SD of three independent replicates. Analysis of variance test was used to evaluate the data using Statistical Analysis System (SAS version 9.2, SAS Institute Inc, Cary, NC, USA, 2009). Treatment mean comparisons were performed with least significant difference test.

\section{RESULTS}

\section{Effect of $\mathrm{AgNO}_{3}$ on phenylpropanoid contents}

Exposure of $R$. pseudoacacia to $\mathrm{AgNO}_{3}$ induced a wide range of responses depending on the $\mathrm{AgNO}_{3}$ concentration; whereas treatments with 10 and $50 \mu \mathrm{M} \mathrm{AgNO}_{3}$ had significant effects on the levels of most of the phenylpropanoid compounds (Figure 2). The total phenylpropanoid contents reached 619.90, 529.63 and $426.42 \mu \mathrm{g} / \mathrm{g}$ dry weight after one, two, and three weeks of exposure to $50.0 \mu \mathrm{M}$ $\mathrm{AgNO}_{3}$, respectively (Figure 2). Among the overall concentrations and exposure times, the highest phenylpropanoid content $(\mu \mathrm{g} / \mathrm{g}$ dry weight) was obtained for rutin (171.96), followed by chlorogenic acid (164.28), epicatechin (128.56), catechin hydrate (84.87), kaempferol (82.05), quercetin (38.34), p-coumaric acid, (15.65) and trans-cinnamic acid (9.13).

However, when compared to the control, caffeic acid showed decreased accumulation in the stressed plant. Most of the phenylpropanoid contents were lower in the plant exposed to relatively higher concentrations of $\mathrm{AgNO}_{3}$ (100 $\mu \mathrm{M})$, except for chlorogenic acid and $p$-coumaric acid. After one and two weeks of exposure to the higher dose, the chlorogenic acid content significantly increased by 54.4 and $69.19 \%$, respectively, compared to that in the control, whereas the $p$-coumaric acid content was higher $(17.3 \%)$ at the initial week of exposure.
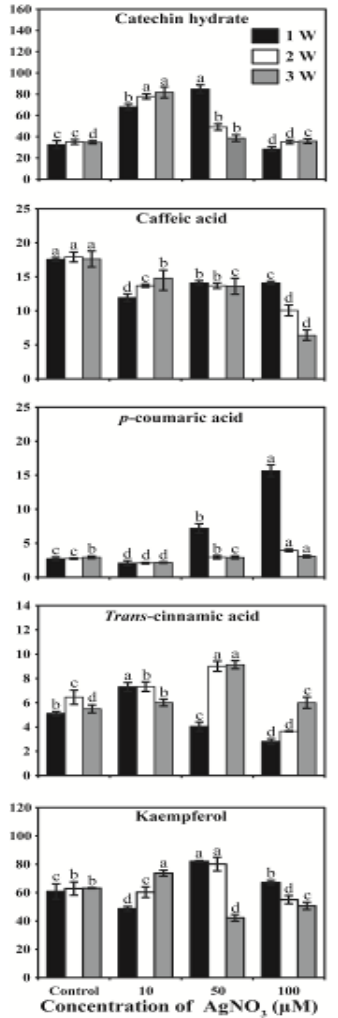
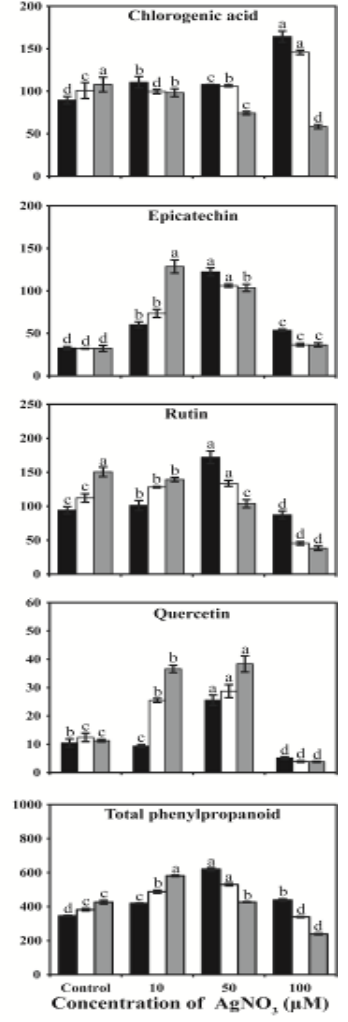

Figure 2: Phenylpropanoid levels ( $\mu \mathrm{g} / \mathrm{g}$ dry weight) in Robinia pseudoacacia after exposure to the redoxactive heavy metal $\mathrm{AgNO}_{3}$ at different concentrations $(10,50$, and $100 \mathrm{mM})$. An untreated R. pseudoacacia plant was used as the control. Samples were harvested after one, two and three weeks of growth under greenhouse conditions, and were subjected to HPLC analysis. The means and standard deviations were attained from three biological replicates. Letters a-d denote significant differences $(p<0.05)$

\section{Effect of $\mathrm{CuCl}_{2}$ on phenylpropanoid contents}

The total phenylpropanoid content was considerably increased in all exposed plants. Among the different $\mathrm{CuCl}_{2}$ concentrations, the cultures exposed to 10 and $50 \mathrm{mM} \mathrm{CuCl}_{2}$ showed higher accumulations, whereas the plant exposed to the highest concentration (100 mM) showed a decreased level (Figure 3). After three weeks of $\mathrm{CuCl}_{2}$ exposure, the total phenylpropanoid content was significantly higher 
in the plants exposed $50 \mathrm{mM}(626.60 \mu \mathrm{g} / \mathrm{g}$ dry weight) and $10 \mathrm{mM}(610.48 \mu \mathrm{g} / \mathrm{g}$ dry weight), whereas the plant exposed to the highest concentration $(100 \mathrm{mM})$ showed a significantly lower accumulation (578.19 $\mu \mathrm{g} / \mathrm{g}$ dry weight). From the overall exposure dose and time, the highest phenylpropanoid content $(\mu \mathrm{g} / \mathrm{g}$ dry weight) was obtained for rutin (236.75) followed by catechin hydrate (163.71), chlorogenic acid (132.39), epicatechin (124.29), kaempferol (86.27), quercetin (31.15), and $p$-coumaric acid (7.34). However, the caffeic acid and transcinnamic acid contents were significantly decreased when compared to those in the control (Figure 3).

\section{Effect of $\mathrm{HgCl}_{2}$ on phenylpropanoid contents}

Among the $\mathrm{HM}$ exposures, $\mathrm{HgCl}_{2}$ showed a slight effect on the accumulation of phenylpropanoids. The total phenylpropanoid production $(\mu \mathrm{g} / \mathrm{g}$ dry weight) was slightly higher at three weeks (463.16), followed by two weeks (440.30) and one week (401.99) of exposure to $0.1 \mathrm{mM} \mathrm{HgCl} 2$, whereas at 0.5 and $1.0 \mathrm{mM}$ exposure, the phenylpropanoid level gradually decreased with increases in the dose and exposure time (Figure 4). In contrast, the plant exposed to $\mathrm{HgCl}_{2}$ showed a slight increase in the phenylpropanoid contents when compared to those in the control, $\mathrm{AgNO}_{3}$ - and $\mathrm{CuCl}_{2}$ - treated plants. From the overall dose and exposure time, the highest phenylpropanoid contents $(\mu \mathrm{g} / \mathrm{g}$ dry weight) was observed for rutin (160.05) followed by chlorogenic acid (108.82), kaempferol (81.04), epicatechin (66.79), catechin hydrate (50.61), quercetin (31.26), trans-cinnamic acid (8.17), and $p$-coumaric acid (4.29). Similar to the above results of $\mathrm{AgNO}_{3}$ and $\mathrm{CuCl}_{2}$ exposure, the caffeic acid content was significantly decreased when compared to that in the control (Figure 4). In addition, most of the phenylpropanoid contents decreased with exposure to $1.0 \mathrm{mM} \mathrm{HgCl}_{2}$.

\section{Effect of redox-active and non-redox-active HMs on phenylpropanoid contents}

Exposure to the HMs showed a broad range of responses, depending on the HM type, concentration and exposure time. From the overall result, $R$. pseudoacacia was notably more sensitive to redox-active $\mathrm{HMs}\left(\mathrm{CuCl}_{2}\right.$ and $\left.\mathrm{AgNO}_{3}\right)$ than to a non-redox-active $\mathrm{HM}\left(\mathrm{HgCl}_{2}\right)$. The total accumulation of phenylpropanoids was higher in the plant exposed to $\mathrm{CuCl}_{2}$, followed by those exposed to $\mathrm{AgNO}_{3}$ and $\mathrm{HgCl}_{2}$ (Figure 2, Figure 3 , and Figure 4). In addition, from the overall HMs, concentration, and exposure time, the increases in phenylpropanoid contents $(\mu \mathrm{g} / \mathrm{g}$ dry weight) were in the following order: chlorogenic acid (164.28), epicatechin (128.56), and quercetin (38.34) were higher in $\mathrm{AgNO}_{3}$ exposed plants; whereas in $\mathrm{CuCl}_{2}$ treatment the rutin (236.75), catechin hydrate (163.71) and kaempferol (86.27) were higher. As mentioned above, $\mathrm{HgCl}_{2}$ exposure did not show a significant accumulation of phenylpropanoids compared to that caused by $\mathrm{AgNO}_{3}$ and $\mathrm{CuCl}_{2}$ exposures. From these results, it is shown that the redoxactive $\mathrm{HMs} \mathrm{AgNO}_{3}$ and $\mathrm{CuCl}_{2}$ had significant effects on the phenylpropanoid contents.

\section{DISCUSSION}

Phenylpropanoid compounds play a potential role in plant responses to environmental stimuli. However, the role of the phenylpropanoid pathway in the survival of $R$. pseudoacacia under unfavorable conditions are poorly understood.
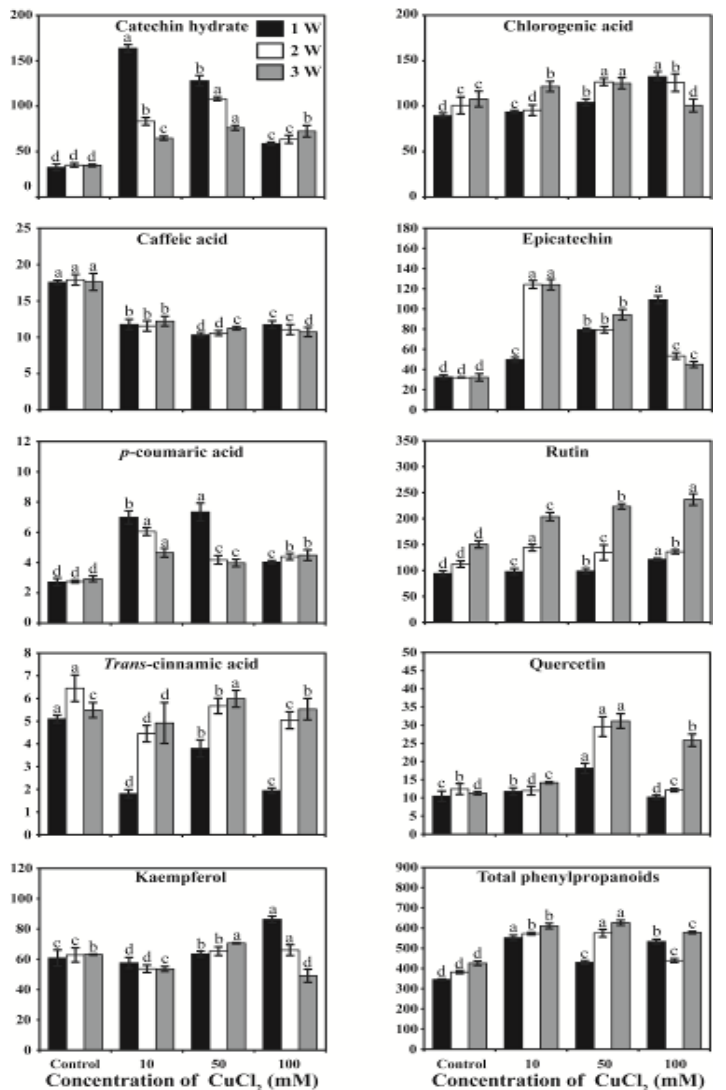

Figure 3: Phenylpropanoid levels ( $\mu \mathrm{g} / \mathrm{g}$ dry weight) in Robinia pseudoacacia after exposure to the redoxactive heavy metal $\mathrm{CuCl}_{2}$ at different concentrations $(10,50$, and $100 \mathrm{mM})$. Untreated $R$. pseudoacacia plant was used as the control. Samples were harvested after one, two and three weeks of growth under greenhouse conditions, and subjected to HPLC analysis. The means and standard deviations were attained from three biological replicates. Letters $a-d$ denotes significant differences $(p<0.05)$ 

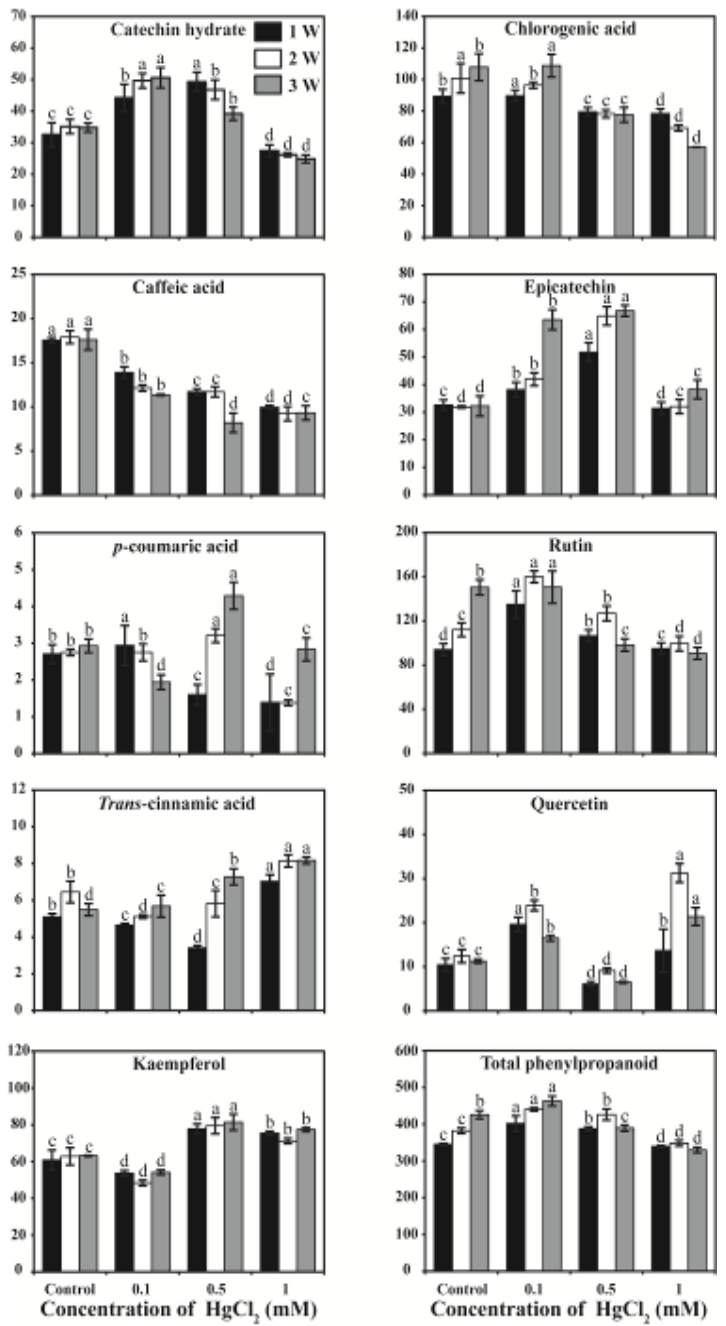

Figure 4: Phenylpropanoid levels ( $\mu \mathrm{g} / \mathrm{g}$ dry weight) in Robinia pseudoacacia after exposure to the redoxactive heavy metal $\mathrm{HgCl}_{2}$ at different concentrations $(0.1,0.5$, and $1 \mathrm{mM})$. An untreated $R$. pseudoacacia plant was used as the control. Samples were harvested after one, two and three weeks of growth under greenhouse conditions, and were used for HPLC analysis. The means and standard deviations were attained from three biological replicates. Letters a-d denotes significant differences $(p<0.05)$.

In this study, using HPLC the accumulation of various phenylpropanoid pathway compounds was investigated after exposure to various HMs.

In this study, exposure of $R$. pseudoacacia to the $\mathrm{HMs} \mathrm{AgNO}_{3}$ and $\mathrm{CuCl}_{2}$, significantly increased the total phenylpropanoid levels in the leaves when compared to that in the unexposed plant. A similar result was obtained when Zea mays was exposed to $\mathrm{Cu}$; the accumulation of total phenolic compounds gradually increased at the initial concentrations (10 and $20 \mathrm{ppm}$ ) but decreased at the higher concentration (50 ppm) [9]. In addition, exposing Lepidium sativum to $\mathrm{CdCl}_{2}$ also increased the total phenolics level at a lower dose $(0.5 \mathrm{mg} / \mathrm{L})$, but showed decreased levels at a higher concentration $(5.0 \mathrm{mg} / \mathrm{L})$. In the same study, it was found that the exposure of this garden cress to selenium increased the total phenolic level [12]. Furthermore, the total phenolic concentration was significantly increased in the leaves of tomato when they were exposed to $2 \mathrm{mM}$ of boron [13].

A recent study also showed that the total phenolic content was significantly increased in Kandelia obovate roots and leaves with increasing $\mathrm{Cd}$ and $\mathrm{Zn}$ concentrations [8]. In addition, the exposure of buckwheat (Fagopyrum esculentum Moench.) to Al significantly increased the accumulation of phenolic compounds and the total phenolic content [14]. Moreover, during long-term water deficits condition, the total phenolic content was increased in the olive Olea europaea [15]. Similarly, when germinated buckwheat (Fagopyrum esculentum Moench.) was subjected to jasmonic acid, chitosan, and salicylic acid treatments, the highest level of phenolic compounds was observed with chitosan and jasmonic acid exposure, whereas salicylic acid did not affect the production of phenolic compounds [16]. In addition, the total phenolic content in the leaves of Erica andevalensis did not show any significant changes when treated with $\mathrm{CdSO}_{4}$ [17]. From these results, it is inferred that the total phenylpropanoid level in $R$. pseudoacacia was increased in the exposed plants when compared to the control. However, the phenylpropanoid content varied based on the HM type and concentration.

It has been reported that abiotic stress in plants leads to an alteration in the composition of phenolic compounds [13]. In this study, some of the specific phenolic compounds were examined. The result showed that the phenylpropanoid compound content changed based on the HM used. In this study, catechin hydrate, chlorogenic acid, epicatechin, rutin, and quercetin were significantly increased with exposure to all HMs tested, whereas only a slight increase in $p$ coumaric acid and kaempferol were observed in the leaves of $R$. pseudoacacia.

Previous studies have reported these phenylpropanoid compounds have strong antioxidant activities [18,19], and their accumulation was increased by exposure to HMs. This shows that the accumulation of various phenylpropanoid compounds is related to the amount of HMs in the organs of the plant $[9,20]$. However, the caffeic acid content significantly decreased after exposure to $\mathrm{HMs}$, 
but the level of trans-cinnamic acid in the leaves of $R$. pseudoacacia changed based on the HM type and concentration. This decrease in the phenylpropanoid contents might be due to decreases in key enzymatic activities related to the phenylpropanoid biosynthetic pathway $[9,21]$. In addition, in this study, the exposure of $R$. pseudoacacia to $\mathrm{HMs}$ did not show any significant changes in shoot and root lengths compared to those in the control (data not shown). This indicates that a significant amount of various phenylpropanoid compounds accumulated in $R$. pseudoacacia to protect them from various HM stresses. As mentioned above, the phenylpropanoid pathway metabolites play a crucial role in various stress conditions. Exposure of Lepidium sativum to $\mathrm{CdCl}_{2}$ decreased the levels of free phenylpropanoid compounds such as caffeic acid and chlorogenic acid in the leaves, whereas these two compounds were increased when they are exposed to $\mathrm{Na}_{2} \mathrm{SeO}_{3}$ [12]. In addition, exposure of Matricaria chamomilla to $\mathrm{NiCl}_{2}$ increased the total phenolic level and chlorogenic acid content in leaves; this accumulation level changed based on the concentration of HMs [20].

Kovacik et al [22] conducted a study on the exposure of $M$. chamomilla to salt stress, the result showed that there was a decrease in the levels of total phenols, caffeic acids, chlorogenic acid and $p$-coumaric acids in the leaves. In addition, when wheat sprouts were treated with different light stress conditions, the contents of $p$ coumaric acid and quercetin were gradually increased with increasing exposure time [11]. The application of $\mathrm{CdSO}_{4}$ increased the rutin level in the leaves of Erica andevalensis. In addition, the chlorogenic acid concentration was increased in $M$. chamomilla exposed to $\mathrm{CuCl}_{2}$, and this increased with increasing $\mathrm{HM}$ concentrations [22].

In an another study, exposure to $\mathrm{Pb}$ resulted in a marked reduction in the caffeic acid level in the shoot of Prosopis farcta, an effect that was also more explicit at higher $\mathrm{Pb}$ concentrations [23]. Likewise, similar responses have been observed in tomato exposed to $\mathrm{Cd}, \mathrm{Cu}$, and $\mathrm{Pb}$ [10]. A similar result was obtained in this study in all of the HM treatments, the caffeic acid content was decreased. However, when R. pseudoacacia was exposed to $\mathrm{CuCl}_{2}$ and $\mathrm{AgNO}_{3}$, the chlorogenic acid and rutin contents were increased, whereas they were significantly decreased with $\mathrm{HgCl}_{2}$ exposure. Overall results showed that phenylpropanoid compounds might be involved in one of the defense mechanisms for plant exposure to redox-active and nonredox-active HMs. Phenylpropanoid compounds can protect the plant from oxidative damage because of their physiological characteristics, such as antimicrobial and antioxidant properties [24]. Phenylpropanoid compounds contain of hydroxyl and carboxyl groups, which are helpful for binding to the HMs [9]. Heavy metals exposure leads to the production of free radicals; phenylpropanoid compounds decay the formation of lipid hydroperoxide by trapping the lipid alkoxyl radicals [25]. Previously, most studies have reported that the exposure of plants to HMs led to the increased production of phenylpropanoid compounds because they play an important role in chelating $\mathrm{HMs}$ and are considered to be electron-donors [9].

In the present study, exposure of $R$. pseudoacacia to redox-active $\mathrm{HMs}\left(\mathrm{CuCl}_{2}\right.$ and $\mathrm{AgNO}_{3}$ ) markedly increased the phenylpropanoid accumulation when compared to that with exposure to non-redox-active $\mathrm{HMs}\left(\mathrm{HgCl}_{2}\right)$. The increase in phenylpropanoid content might be that redox-active $\mathrm{HMs}$ can cause oxidative damage directly to cells via the Haber-Weiss and Fenton reactions [26,27]; which leads to excessive reactive oxygen species (ROS) production in plants, this may trigger programmed cell death. Thus, after redox-active HM exposure, the phenylpropanoid contents increased significantly to protect $R$. pseudoacacia from oxidative damage. In contrast, non-redox-active HMs indirectly induce oxidative stress $[26,27]$. This could also be one of the reasons that non-redox- active HMs did not have significant effect on the phenylpropanoid levels in R. pseudoacacia. A schematic representation of the metabolic process of the phenylpropanoid pathway against HMs is shown in Figure 5.

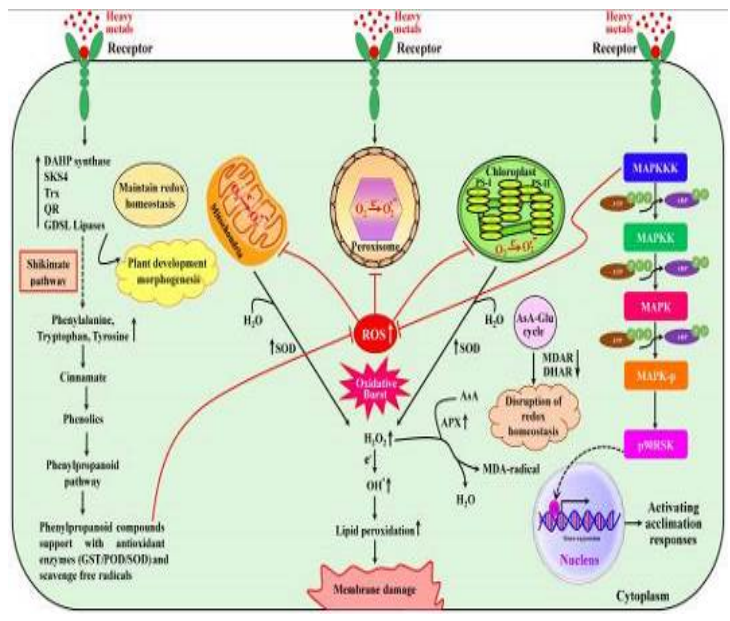

Figure 5: Schematic representation of the various biological mechanisms that are affected by heavy metal toxicity in plants. Exposure to heavy metal will lead to toxic effects to cells such as increased ROS 
production, interference of redox homeostasis, lipid peroxidation, diminished mitochondrial function, and membrane damage. Black upward and downward arrows indicate the increase and decrease in the protein level after exposure to heavy metal stress, respectively. Black dotted arrow denotes shikimate pathway, a common biosynthetic pathway for the synthesis of aromatic amino acids. Abbreviations: ADP Adenosine diphosphate; APX, ascorbate peroxidase; AsA, reduced ascorbate; ATP Adenosine triphosphate; DAHP, 3-deoxy-D-arabino-heptulosonate-7phosphate; DHAR dehydroascorbate reductase; Glu, glutathione; GST, glutathione S-transferase; $\mathrm{H}_{2} \mathrm{O}_{2}$, hydrogen peroxide; MAPK, mitogen-activated protein kinase; MAPKK MAPK-kinases; MAPKKK, MAPKKkinases; MDA malondialdehyde; MDAR, monodehydroascorbate reductase; p90RSK, p90 ribosomal S6 kinase; $\mathrm{PO}$, peroxidase; PS, photosystem; QR, quinone reductase; ROS, reactive oxygen species; SKS4, SKU5 similar 4 protein; SOD superoxide dismutase; TF transcription factor; Trx, thioredoxin

\section{CONCLUSION}

The findings of this study indicate that the accumulation of phenylpropanoid compounds differs according to redox-active and non-redoxactive HMs. These findings afford new knowledge and direction for the future study of the mechanism of $\mathrm{HM}$ tolerance in forest ecosystems. Further studies are necessary to clarify the variation in phenylpropanoid compounds.

\section{DECLARATIONS}

\section{Acknowledgement}

This work was supported by R\&D Program for Forest Science Technology (project no. 2018112D10-1920-BB01) of Korea Forest Service (KFS), Republic of Korea.

\section{Conflict of interest}

No conflict of interest is associated with this work

\section{Contributions of authors}

We declare that this work was done by the authors named in this article and all liabilities pertaining to claims relating to the content of this article will be borne by the authors. †These authors (NSK and RS) contributed equally to this work. SUP and BBP conceived and designed the study, NSK, RS, SWC, and WBY performed the experiments and analyzed the data, RS and SUP wrote the manuscript. All authors read and approved the manuscript for publication.

\section{Open Access}

This is an Open Access article that uses a funding model which does not charge readers or their institutions for access and distributed under the terms of the Creative Commons Attribution License (http://creativecommons.org/licenses/by/ 4.0) and the Budapest Open Access Initiative (http://www.budapestopenaccessinitiative.org/rea d), which permit unrestricted use, distribution, and reproduction in any medium, provided the original work is properly credited.

\section{REFERENCES}

1. Fargasova A. Toxicity comparison of some possible toxic metals ( $\mathrm{Cd}, \mathrm{Cu}, \mathrm{Pb}, \mathrm{Se}, \mathrm{Zn}$ ) on young seedlings of Sinapis alba L. Plant Soil Environ 2004; 50: 33-38.

2. Lombardi L, Sebastiani L. Copper toxicity in Prunus cerasifera: growth and antioxidant enzymes responses of in vitro grown plants. Plant Sci 2005; 168: 797-802.

3. Fan MC, Xiao X, Guo YQ, Zhang J, Wang ET, Chen WM, Lin YB, Wei GH. Enhanced phytoremediation of Robinia pseudoacacia in heavy metal-contaminated soils with rhizobia and the associated bacterial community structure and function. Chemosphere 2018; 197: 729740.

4. Yang $Y R$, Song $Y Y$, Scheller HV, Ghosh A, Ban $Y H$, Chen $H$, Tang $M$. Community structure of arbuscular mycorrhizal fungi associated with Robinia pseudoacacia in uncontaminated and heavy metal contaminated soils. Soil Biol Biochem 2015; 86: 146-158.

5. Zhao J, Davis LC, Verpoorte R. Elicitor signal transduction leading to production of plant secondary metabolites. Biotechnol Adv 2005; 23: 283-333.

6. Biala W, Jasinski M. The Phenylpropanoid Case - It Is Transport That Matters. Front Plant Sci 2018; 9.

7. Clemens S, Weber M. The essential role of coumarin secretion for $\mathrm{Fe}$ acquisition from alkaline soil. Plant Signal Behav 2016; 11.

8. Chen S, Wang Q, Lu HL, Li JW, Yang D, Liu JC, Yan CL. Phenolic metabolism and related heavy metal tolerance mechanism in Kandelia obovata under $\mathrm{Cd}$ and $\mathrm{Zn}$ stress. Ecotox Environ Safe 2019; 169: 134-143.

9. Kisa D, Elmastas M, Ozturk L, Kayir O. Responses of the phenolic compounds of Zea mays under heavy metal stress. Appl Biol Chem 2016; 59: 813-820.

10. Kisa D, Kayır O, Sağlam N, Şahin S, Öztürk L, Elmastaş M. Changes of phenolic compounds in tomato associated with the heavy metal stress. JONAS 2019; 2: 35-43.

11. Cuong D, Ha TW, Park CH, Kim NS, Yeo HJ, Chun SW, Kim C, Park SU. Effects of LED lights on expression of genes involved in phenylpropanoid biosynthesis and accumulation of phenylpropanoids in wheat sprout. Agronomy 2019; 9.

12. Elguera JCT, Barrientos EY, Wrobel K, Wrobel K. Effect of cadmium $(\mathrm{Cd}(\mathrm{II}))$, selenium $(\mathrm{Se}(\mathrm{IV}))$ and their

Trop J Pharm Res, May 2020; 19(5): 1071 
mixtures on phenolic compounds and antioxidant capacity in Lepidium sativum. Acta Physiol Plant 2013; 35: 431-441.

13. Cervilla $L M$, Blasco $B$, Rios JJ, Rosales MA, SanchezRodriguez E, Rubio-Wilhelmi MM, Romero L, Ruiz JM. Parameters symptomatic for boron toxicity in leaves of tomato plants. J Bot 2012; Article ID 726206: 17 pages.

14. Smirnov OE, Kosyan AM, Kosyk OI, Taran NY. Response of phenolic metabolism induced by aluminium toxicity in Fagopyrum esculentum moench. plants. Ukr Biochem J 2015; 87: 129-135.

15. Petridis A, Therios I, Samouris G, Koundouras S, Giannakoula A. Effect of water deficit on leaf phenolic composition, gas exchange, oxidative damage and antioxidant activity of four Greek olive (Olea europaea L.) cultivars. Plant Physiol Bioch 2012; 60: 1-11.

16. Park $\mathrm{CH}$, Yeo HJ, Park YE, Chun SW, Chung YS, Lee SY, Park SU. Influence of chitosan, salicylic acid and jasmonic acid on phenylpropanoid accumulation in germinated buckwheat (Fagopyrum esculentum Moench). Foods 2019; 8.

17. Marquez-Garcia G, Fernandez-Recamales MA, Cordoba F. Effects of cadmium on phenolic composition and antioxidant activities of Erica andevalensis. J Bot 2012; Article ID 936950: 6 pages.

18. Shen $Y B$, Song $X$, Li L, Sun J, Jaiswal Y, Huang JQ, Liu $C$, Yang WJ, Williams $L$, Zhang $H$, et al. Protective effects of p-coumaric acid against oxidant and hyperlipidemia-an in vitro and in vivo evaluation. Biomed Pharmacother 2019; 111: 579-587.

19. Xu D, Hu MJ, Wang YQ, Cui YL. Antioxidant activities of quercetin and its complexes for medicinal application. Molecules 2019; 24.
20. Kovacik J, Klejdus B, Backor M. Phenolic metabolism of Matricaria chamomilla plants exposed to nickel. J Plant Physiol 2009a; 166: 1460-1464.

21. Chung IM, Kim JJ, Lim JD, Yu CY, Kim SH, Hahn SJ. Comparison of resveratrol, SOD activity, phenolic compounds and free amino acids in Rehmannia glutinosa under temperature and water stress. Environ Exp Bot 2006; 56: 44-53.

22. Kovacik J, Gruz J, Backor M, Tomko J, Strnad M, Repcak M. Phenolic compounds composition and physiological attributes of Matricaria chamomilla grown in copper excess. Environ Exp Bot 2008; 62: 145-152.

23. Zafari S, Sharifi M, Chashmi NA, Mur LAJ. Modulation of Pb-induced stress in Prosopis shoots through an interconnected network of signaling molecules, phenolic compounds and amino acids. Plant Physiol Bioch 2016; 99: 11-20.

24. Balasundram N, Sundram K, Samman S. Phenolic compounds in plants and agri-industrial by-products: Antioxidant activity, occurrence, and potential uses. Food Chem 2006; 99: 191-203.

25. Michalak A. Phenolic compounds and their antioxidant activity in plants growing under heavy metal stress. Pol J Environ Stud 2006; 15: 523-530.

26. Sathasivam $R, \quad K i \quad J S$. Differential transcriptional responses of carotenoid biosynthesis genes in the marine green alga Tetraselmis suecica exposed to redox and non-redox active metals. Mol Biol Rep 2019a; 46: 1167-1179.

27. Sathasivam R, Ki JS. Heat shock protein genes in the green alga Tetraselmis suecica and their role against redox and non-redox active metals. Eur $J$ Protistol 2019b; 69: 37-51. 